\title{
Effect of Aggregate Maximum Size upon Compressive Strength of Concrete
}

\author{
Ismaeel H. Musa Albarwary \\ Dept. of Road Construction \\ Duhok Technical Institute \\ Duhok Polytechnic University
}

\author{
Ziyad N. Shamsulddin Aldoski \\ Dept. of Building and Construction \\ Duhok Technical Institute \\ Duhok Polytechnic University
}

Lawend K. Askar

Dept. of Highway and Bridges

Technical College of Engineering

Duhok Polytechnic University

\section{ABSTRACT}

Aggregates form $60 \%$ to $75 \%$ of concrete volume and thus influence its mechanical properties. The strength of normal concrete is affected by the maximum size of a well-graded coarse aggregate by two opposing ways. Concrete mixes containing larger aggregate particles needs less mixing water than those containing smaller aggregates. On the other hand, the smaller size aggregates give larger surface area for bonding with the mortar matrix. This study is a trial to cover these two points with testing three different useable concrete mixes in Kurdistan RegionIraq which are 1:1.5:3, 1:2:4 and 1:3:6 (Cement: Sand: Gravel). In each mix, five maximum aggregate sizes were used which are $9.5 \mathrm{~mm}, 12.5 \mathrm{~mm}, 19 \mathrm{~mm}, 25 \mathrm{~mm}$ and $37.5 \mathrm{~mm}$, the consistency of the all mixes is fixed for slumps of $25-50 \mathrm{~mm}$. According to the test results it is concluded that in general the compressive strength of concrete increases when the maximum size of aggregate decreases and the maximum aggregate size strongly influences the concrete strength. Test results also show that the optimum concrete strength is reached by using aggregates of $9.5 \mathrm{~mm}$ maximum size. We further concluded that for a specified strength, an economical mix can be produced by decreasing the amount of cement and using an appropriate maximum aggregate size.

KEY WORDS: Concrete, aggregate size, compressive strength, coarse aggregate, Models.

\section{INTRODUCTION}

Aggregates form 60 to 75 percent of concrete volume and thus influences its mechanical properties.

The strength of normal concrete is affected by the maximum size of a wellgraded coarse aggregate by two opposing ways. Concrete mixes containing larger aggregate particles needs less mixing water than those containing smaller aggregates. On the other hand, the smaller size aggregates give larger surface area for bonding with the mortar matrix.

Several researches had been done on the effect of the maximum aggregate size (MAS) on concrete compressive strength. The conclusions of these investigations differ from one to another as shown below;

Kozul and Drawin (1) studied the compressive strength and fracture of concrete and how the aggregate type, size, and content affects these concrete properties. They used basalt or crushed limestone aggregate with sizes of $12 \mathrm{~mm}$ or $19 \mathrm{~mm}$.

They concluded that for both normal and high-strength concretes the compressive strength is little affected by aggregate size, while the flexure strength of the both concretes is not affected by the aggregate size.

Yousif et. al. ${ }^{(2)}$ investigated the influence of changing specimen size and aggregate size on concrete compressive strength and modulus of elasticity. They used 4.75, 9.5, 19.0, 37.5, and 75-mm nominal maximum size aggregates in the concrete samples. The outcome of this study shows that strength ratio was increases when the nominal maximum aggregate size is increases in the concrete at each testing date and the strength ratio decreased when nominal 
maximum aggregate size is decreased. Tumidajski and Gong ${ }^{(3)}$ in their research studied the variation of compressive strength and workability of concrete with the size of coarse aggregate.In their study the concrete was made by using different proportions of 37.5 and $19.5 \mathrm{~mm}$ stones as coarse aggregate. Their test results show that by using cement content of 160 $\mathrm{kg} / \mathrm{m}^{3}$ and (w/c) greater than 0.9 , the compressive strength is maximum at 25 percent by weight of $37.5 \mathrm{~mm}$ stone. While for the cement content of $350 \mathrm{~kg} / \mathrm{m} 3$ and w/c ratios of less than 0.50 , maximum compressive strength is substantively reduced. Ioannides, and Mills ${ }^{(4)}$ examined the effect of the type and size of coarse aggregate on properties of concrete, (compressive and flexural strengths and modulus of elasticity). In their results they concluded that the coarse aggregates graduation had little effect on the properties of concrete, they also showed that using larger sized coarse aggregates in pavements and highway structures does not significantly affect the mechanical properties of concrete.

Jimoh and Awe ${ }^{(5)}$ investigated the effect of aggregate size and type on the compressive strength of concrete, they used four aggregate types which are sand, quarry dust, gravel and granite, while sizes used were 20 and $28 \mathrm{~mm}$ of coarse aggregate. Their test results show that the use of quarry dust and granite of $20 \mathrm{~mm}$ size improves the concrete strength $34 \%$ over strength of concrete produced by concrete with sand and gravel of $28 \mathrm{mmm}$.They concluded that concrete strength decreases when the coarse aggregate size increases, Yaqub and Bukhri ${ }^{(6)}$ concluded that concrete with a mixture of $10 \mathrm{~mm}$ and $5 \mathrm{~mm}$ aggregates gave higher compressive strength than other types of aggregates when they tested the effect of aggregate sizes on the compressive strength of high compressive strength using $37.5 \mathrm{~mm}, 25 \mathrm{~mm}$, $20 \mathrm{~mm}, 10 \mathrm{~mm}$, and $5 \mathrm{~mm}$ coarse aggregates.

Kumar and Krishna ${ }^{(7)}$ made a study on the influence of aggregate size on strength and sorptivity charsterstics of light weight concrete made from cinder aggregates.

They found that light weight concrete of grade 20Mpa could be developed with $12.5 \mathrm{~mm}$ aggregate size while using aggregate of $10 \mathrm{~mm}$ size produces concretes of 30 Mpa grade. Krishna, et. al. ${ }^{(8)}$ Investigated the effect of coarse aggregate sizes of $(20 \mathrm{~mm} ; 16 \mathrm{~mm}$; $12.5 \mathrm{and} 10 \mathrm{~mm})$ on properties of both normal and selfcompacting concrete. The main conclusions of them are that the all the strengths (compressive strength, split tensile strength, and flexural strength) of both normal concrete and (SCC) are achieved by using coarse aggregate of $20 \mathrm{~mm}$ maximum size and the increase in strength of concrete is proportional to the size of coarse aggregate directly.

Ajamu and Ige $^{(9)}$ examine the effect of the size of coarse aggregate upon the compressive and flexural strengths of concrete beams and cubes, in this study they examined concrete cubes and beams with different aggregate sizes of $9 \mathrm{~mm}, 13.2 \mathrm{~mm}$, $19 \mathrm{~mm}, 25 \mathrm{~mm}$, and $37.5 \mathrm{~mm}$.

Their results depicted that the increase in coarse aggregate size increases the compressive strength of concrete and decreases its flexural strength.

Woode et. al. ${ }^{(10)}$ conducted an experiment to determine the effect aggregates sizes ( $10 \mathrm{~mm}, 14 \mathrm{~mm}$ and $20 \mathrm{~mm}$ ) on the compressive strength of concrete at different ages (7,14,21 and28 days). The concrete was made from crushed gneisses aggregates which are used in gana for concrete production. Their results show that the concrete made with $10 \mathrm{mmm}$ maximum aggregate have higher than the concrete 
made from aggregates of $14 \mathrm{~mm}$ and $20 \mathrm{~mm}$ sizes and for the best compressive strength at 28 days, the maximum aggregate size of 8 mm must be used for water- cement ratio of 0.63.

With respect to the aforementioned studies, no investigation had been done to overcome the main two opposite affects of the (MAS) on concrete strength namely minimizing the water demand using larger coarse aggregate and enlarging bond area using smaller coarse aggregate.

Current study is a trial to cover these two points with testing three different useable concrete mixes in Kurdistan Region -Iraq which are 1:1.5:3, 1:2:4 and 1:3:6 (Cement: Sand: Gravel). In each mix, five maximum aggregate sizes were used which are $9.5 \mathrm{~mm}, 12.5 \mathrm{~mm}, 19 \mathrm{~mm}, 25 \mathrm{~mm}$ and $37.5 \mathrm{~mm}$. As the water to cement ratio affects concrete compressive strength inversely, and to minimize this effect on variation of the compressive strength of the different mixes, the degree of workability for all mixes was fixed for slumps of 25$50 \mathrm{~mm}$ which are low workable concretes according to Nivlle ${ }^{(14)}$.

This study is regarded as a trial to develop more economical mixes for concrete structures by decreasing the amount of cement and using a suitable maximum aggregate to get a specified strength.

\section{EXPERIMENTAL PROGRAM}

In order to examine the effect of maximum size of coarse aggregate on compressive strength an experimental program was planned.

A total of 45 concrete cubical specimens $(150 * 150 * 150 \mathrm{~mm})$ in dimensions were casted and tested after 28 days of water curing. These concrete specimens were divided into three groups, one group for each mix of the three mixes. Each group includes (15) cubes to cover the five aggregate sizes which were used .The program is shown in table (1).

\subsection{MATERIALS AND METHODS MATERIAS}

\subsubsection{Cement:}

Ordinary Portland Cement was used throughout this research. The cement was sourced from Turkish and has a specific gravity of 3.12.

\subsubsection{Aggregate:}

The fine aggregate is locally river sand obtained from al-khazer area with a fineness modulus of (2.6).

The coarse aggregate is also obtained from al-khazer area. This aggregate was an Iraqi rounded river gravel, with maximum aggregate sizes of (37.5) $\mathrm{mm}$ and less.

\subsubsection{Water:}

Potable drinking water is used throughout this work.

More details about the properties of the materials used in current work are given in table (2).

Table (1): Variables which has been studied in the present investigation

\begin{tabular}{|c|c|c|c|}
\hline $\begin{array}{c}\text { Mixes } \\
\text { Groups }\end{array}$ & $\begin{array}{c}\text { Mix } \\
\text { proportions }\end{array}$ & $\begin{array}{c}\text { M.A.S. } \\
(\mathbf{m m})\end{array}$ & $\begin{array}{c}\text { Slump } \\
(\mathbf{m m})\end{array}$ \\
\hline \multirow{4}{*}{ Group (1) } & \multirow{3}{*}{$1: 1.5: 3$} & 37.5 & $25-50$ \\
\cline { 3 - 4 } & & 25 & $25-50$ \\
\cline { 3 - 4 } & & 19 & $25-50$ \\
\cline { 3 - 4 } & & 12.5 & $25-50$ \\
\hline \multirow{4}{*}{ Group (2) } & \multirow{3}{*}{$1: 2: 4$} & 9.5 & $25-50$ \\
\cline { 3 - 4 } & & 37.5 & $25-50$ \\
\cline { 3 - 4 } & & 25 & $25-50$ \\
\hline \multirow{3}{*}{ Group (3) } & & 19 & $25-50$ \\
\cline { 3 - 4 } & & 12.5 & $25-50$ \\
\cline { 3 - 4 } & \multirow{3}{*}{$1: 3: 6$} & 9.5 & $25-50$ \\
\cline { 3 - 4 } & & 37.5 & $25-50$ \\
\cline { 3 - 4 } & & 25 & $25-50$ \\
\cline { 3 - 4 } & & 19 & $25-50$ \\
\cline { 3 - 4 } & & 12.5 & $25-50$ \\
\cline { 3 - 4 } & & 9.5 & $25-50$ \\
\hline
\end{tabular}




\begin{tabular}{|c|c|c|c|}
\hline Material & Test & Vale & Unit \\
\hline \multirow[t]{2}{*}{ Cement } & Fineness & 3400 & $\mathrm{~cm}^{2} / \mathrm{gm}$ \\
\hline & Specific Gravity & 3.12 & \\
\hline \multirow[t]{4}{*}{ Sand } & Specific Gravity & 2.68 & \\
\hline & $\begin{array}{l}\text { Fineness } \\
\text { modulus }\end{array}$ & 2.6 & \\
\hline & Moisture content & 0.5 & $\%$ \\
\hline & Absorption & 2.31 & $\%$ \\
\hline \multirow[t]{4}{*}{ Gravel } & Specific Gravity & 2.67 & \\
\hline & $\begin{array}{l}\text { Fineness } \\
\text { modulus }\end{array}$ & 7.2 & \\
\hline & Moisture content & 0.25 & $\%$ \\
\hline & Absorption & 0.93 & $\%$ \\
\hline
\end{tabular}

Table (2): Properties of the Materials Used

\subsection{METHOD}

\subsubsection{Mixture Proportions}

Three mix ratios of $(1: 1.5: 3),(1: 2: 4)$ and (1:3:6) (Cement: Fine Aggregate: Coarse Aggregate) were examined in this work and the degree of workability of the all mixes were kept constant between (2550mm).

\subsubsection{Casting, Curing and Testing of Specimen}

Concrete specimens were made according to BS 1881-108 (1983). ${ }^{12)}$

The required weights of concrete ingredients were measured and mixing was done by an electrical mixer to ensure the homogeneity of the mixes, the degree of workability of all mixes were kept constant and measured by the slump test in accordance to ASTM C143-Slump of Portland Cement Concrete.

For each mix and each (MAS) of coarse aggregate 3 cubes $(150 * 150 * 150 \mathrm{~mm})$ were casted. After casting by one day, the concrete cubes were removed from the molds and were transferred to a water tank to be cured until the time of test which is fixed as (28 days). The curing of the cubes was done by immersing them in water tank. The concrete samples were tested for compressive strength at 28 days according to BS1881-116 (1983). ${ }^{(13)}$

For each variable, three samples were tested using a universal compressive testing machine and the average value for the three cubes was taken.

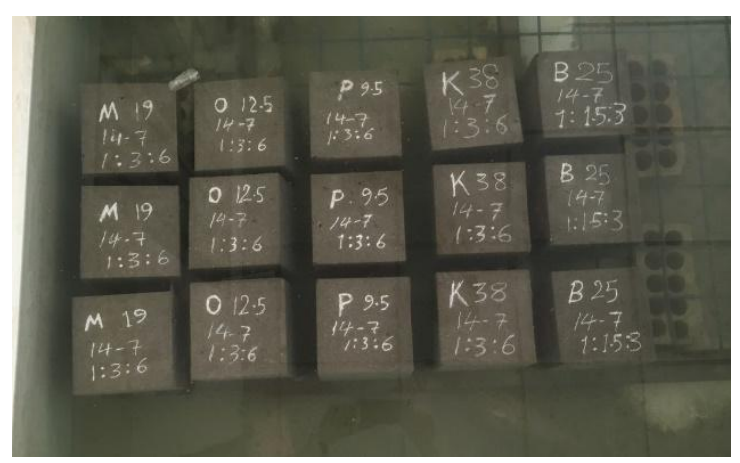

Figure (1): Specimens Curing

\subsubsection{Maximum Aggregate Size (MAS)}

Maximum aggregate size (MAS) according the specification CT $382(2003)$ is defined as the smallest sieve size that requires $100 \%$ passing, while the nominal aggregate size is defined as one sieve size smaller than the maximum aggregate size.

In this research the largest aggregate size was taken according to the maximum aggregate size definition which is the size of the smallest sieve through which the whole aggregate is passing.

\section{RESULTS AND DISCUSSION}

\subsection{Effect of maximum aggregate size}

Figure (2) illustrates the effect of varying maximum aggregate size on compressive strength of the concrete mixture 1:1.5:3. From this figure it appears that, when the maximum size of aggregate decreases the compressive strength increases. This confirms with results of Jimoh $^{(5)}$, Yaqyb ${ }^{(6)}$, Woode $^{(10)}$, and Shetty ${ }^{(14)}$.

The increase in the strength is due to two reasons:-

1. Concrete made with smaller coarse aggregate size gives higher strength than concrete made with bigger size of coarse 
aggregate due to the weak bonds in the later resulting from greater heterogeneity, internal bleeding and the development of micro cracks ${ }^{(14)}$.

2. The smaller nominal maximum size has a larger surface compared with the larger nominal maximum size which makes a high bonding strength at the interface zone around the aggregate particles when concrete is under loading, so as bond failure is avoided and the fracture surfaces pass through the aggregate as well as through the hardened cement paste both under compressive and under tensile loading ${ }^{(15)}$.

Figure (2) also shows that by using $19 \mathrm{~mm}$, the increase in compressive strength is about $10 \%$ compared to compressive strength of the same concrete which includes $37.5 \mathrm{~mm}$ maximum aggregate size.

The maximum compressive strength (32.92 MPa) was obtained by using $9.5 \mathrm{~mm}$ aggregate in this mix; this strength is $\mathbf{2 8 \%}$ higher than that of the concrete with $\mathbf{3 7 . 5}$ mm maximum aggregate size.

From the analysis of test results it is shown that this polynomial equation $(\mathrm{Y}=0.0107 \mathrm{X} 2-0.7344 \mathrm{X}+38.239$ with $\mathrm{R} 2=$ 0.9573 ) is the best relation between the concrete compressive strength and the maximum aggregate size.

Figure (3) is the chart of compressive strength of mix 1:2:4 against maximum aggregate size. This figure shows that compressive strength of concrete continuously increases due to the decrease in the maximum aggregate size. For this mix, the increase in the strength is about 18 $\%$ when using $19 \mathrm{~mm}$ instead of $37.5 \mathrm{~mm}$, while this increase rises to $30 \%$ by replacing aggregates of $9.5 \mathrm{~mm}$ maximum size instead of $37.5 \mathrm{~mm}$ maximum size.

The regression analysis for the results of this mix shows that the best relation between concrete compressive strength and the maximum aggregate size was according the logarithmic equation $(y=-4.596 \ln (X)$ +39.348 with $R 2=0.9454$ ).
The compressive strength results for the lean mix 1:3:6 with five different maximum aggregate sizes are shown in figure (4), this figure clears that the change in compressive strength with the aggregates size have the same trend with one exception which is that the aggregates of $37.5 \mathrm{~mm}$ maximum size gives higher strength than the aggregates of $25 \mathrm{~mm}, 19 \mathrm{~mm}$ and $12.5 \mathrm{~mm}$ maximum sizes, this finding agrees with Shetty ${ }^{(17)}$ as he stated that in lean mixes larger aggregate gives highest strength.

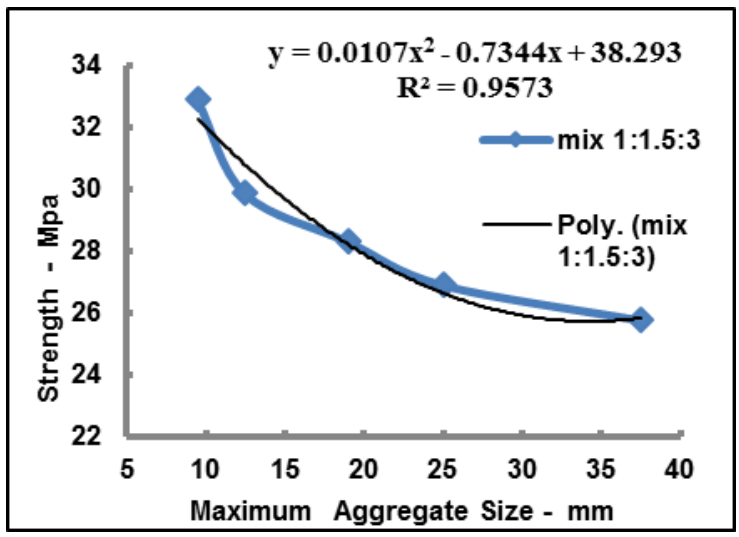

Figure (2): Variation of concrete strength with MAS for mix 1:1. 5:3

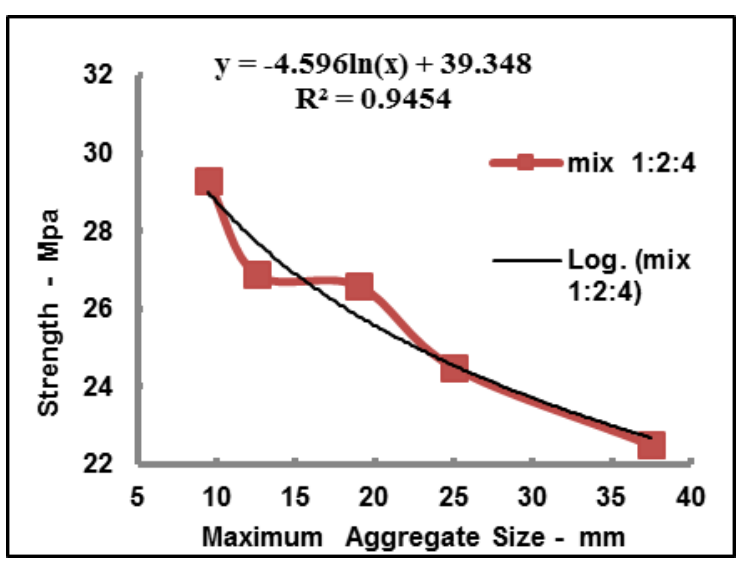

Figure (3): Variation of concrete strength with MAS for mix 1:2:4

For this mix, the optimum strength also occurs when using $9.5 \mathrm{~mm}$, while the minimum strength, which is also greater than the structural concrete strength limit (>17MPa) occurs when using $25 \mathrm{~mm}$. 
After analyzing the results of this mix it was shown that the polynomial equation $(\mathrm{Y}=\mathbf{0 . 0 2 3 2 X 2}-\mathbf{1 . 1 4 5 X}+\mathbf{3 2 . 2 3 6}$ with $R 2=0.9887$ ) was the best relation between the compressive strength and the maximum aggregate size.

Finally it can be concluded that for the all mixes and all the tested aggregate sizes, aggregates of $9.5 \mathrm{~mm}$ maximum size gives the optimum compressive strength to the concrete.

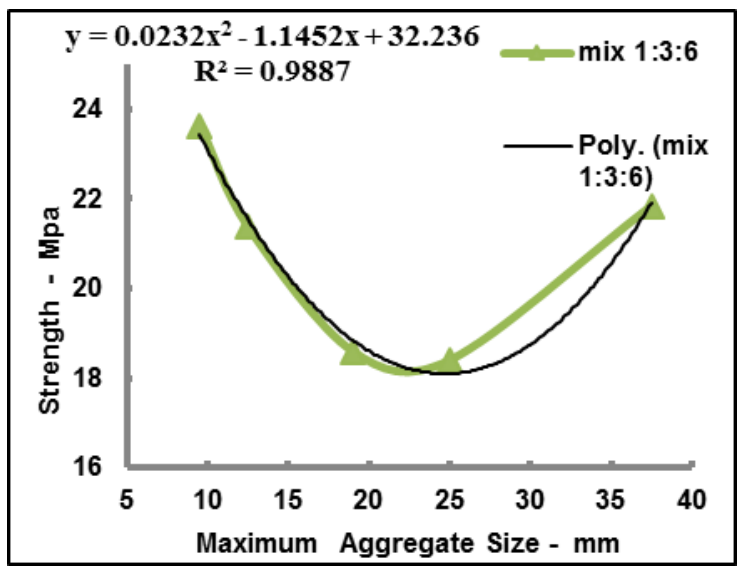

Figure (4): Variation of concrete strength with MAS for mix 1:3:6

\section{$\underline{\text { Effect of mix proportions }}$}

Figure (5) shows the compressive strength variation of the all mixes with different maximum aggregate sizes. From this figure, we can see that the maximum aggregate size strongly influences the concrete strength.

Observing the results in figure (6), it is shown that the maximum aggregate size effect on concrete strength emulates the cement content factor effect, as it is clear from the comparison of the strength of mix 1:1.5:3 with coarse aggregate of $37.5 \mathrm{~mm}$ maximum size which gives less strength than of the mix 1:2:4 with coarse aggregate of $9.5 \mathrm{~mm}$ maximum size.

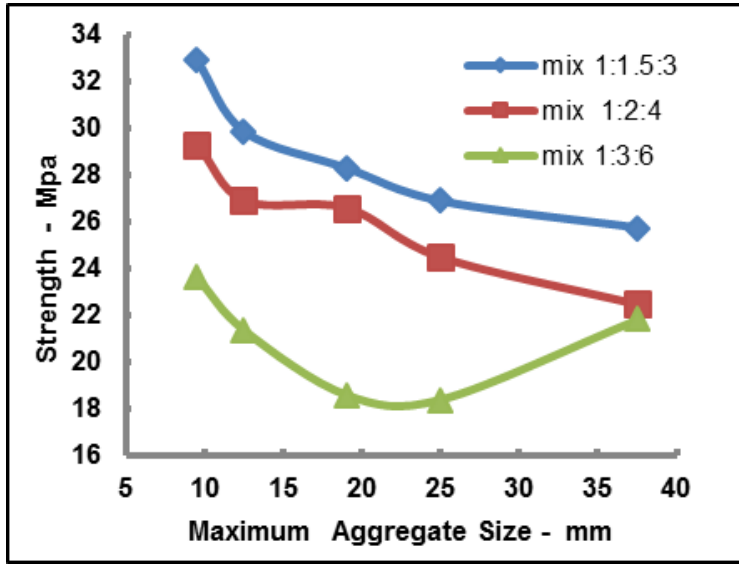

Figure (5): Variation of the compressive strength of the all mixes with different maximum aggregate sizes

These results show that there is an ability to produce economical mixes by producing normal concrete of same strength as rich concrete when selecting a suitable maximum aggregate size, as in using aggregates of $19 \mathrm{~mm}$ maximum size in 1:2:4 which give about the same strength of mix 1:1.5:3 with $37.5 \mathrm{~mm}$ maximum size aggregates.

The production of concrete by this method will have another advantage which is, reducing the risk of thermal cracking due to a temperature peak caused by the heat of hydration of cement in rich mixes.

It is clear that below the cement to aggregate ratio $(\mathrm{C} / \mathrm{A}=6)$, the concrete strength is more affected by the change in the aggregate size than the cement content. 


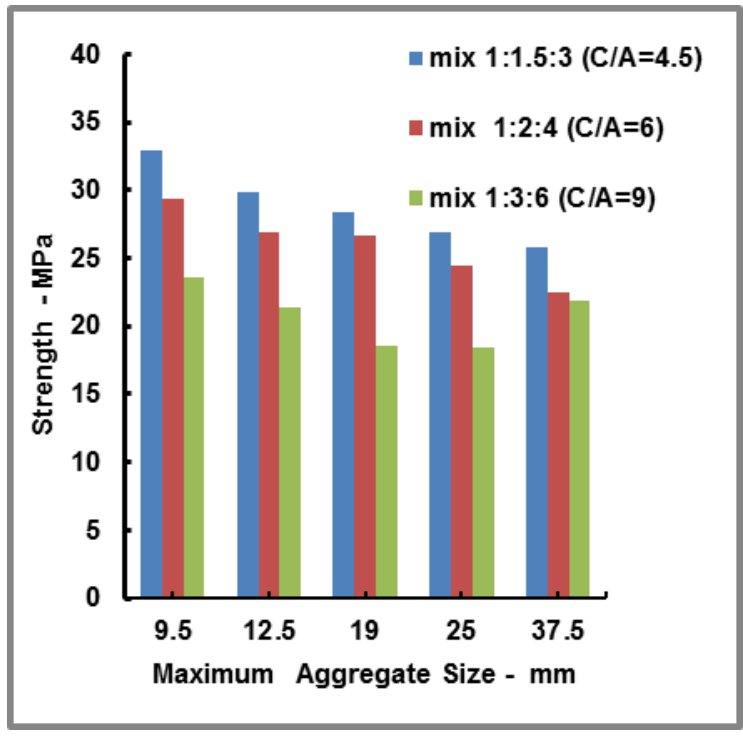

Figure (6): Variation of concrete strength with MAS for the three mixes $1: 1.5: 3,1: 2: 4$ and 1:3:6

\section{CONCLUSION}

1. In general the concrete compressive strength increases when the maximum size of aggregate decreases.

2. The maximum aggregate size strongly influences the concrete strength.

3. The optimum compressive strength of concrete is reached by using aggregates of $9.5 \mathrm{~mm}$ maximum size.

4. For concrete of cement to aggregate ratio below (6), the compressive strength is more affected by the change in the aggregate size than the cement content.

5. For a specified strength, an economical mix can be produced by increasing the cement to aggregate ratio and decreasing the maximum size of aggregate.

6. Lean mixes can be used for structural purposes when using small sized aggregates.

\section{ACKNOWLEDGMENTS}

The authors are very grateful to the two technicians Mr. Heja Ahmed and Mr. Khalid Khalil, who are working in concrete Laboratory at Duhok
Technical Institute for their assistance in testing the concrete cubes.

\section{REFERENCES}

1. Rozali kozul and David drawin, "Effects of Aggregate Type, Size and Content on Concrete Strength and Fracture Energy", the reinforced concrete research council, project 56, June 1997.

2. Yousif A. A., Isaa M. A., others, "Specimen and Aggregate Size Effect on Concrete Compressive Strength", cement concrete and aggregates journal 22 (3), 2000.

3. Tumidajski P.J. and Gong B., "Effect of Coarse Aggregate Size on Strength and Workability of Concrete", Canadian Journal of Civil Engineering, 76-78, 2006.

4. Ioannides, A.M. and Mills, J.C. (2006), "Larger Sized Coarse Aggregates in Portland Cement Concrete Pavement and Structures", Report No. FHWA/OH-2006/10A, Ohio Department of Transportation, Columbus, $\mathrm{OH}$.

5. Jimoha A. A, and Awe S. S., "A Study of the Influence of Aggregate Size and Type on the Compressive Strength of Concrete", Journal of Research Information in Civil Engineering, 4 (2), 2007.

6.

aqub M. and Bukhari I., "Effect of Size of Coarse Aggregate on Compressive Strength of High Strength Concretes", $31^{\text {st }}$ Conference on Our Word in Concrete and Structures: 16-17 August 2006, singapore

7. Kumar R. P.1 and Krishna R. M. V. "A Study on the Effect of Size of Aggregate on the Strength and Sorptivity Characteristics of Cinder Based Light Weight Concrete", Research Journal of Engineering Sciences, 1 (6), 2012.

8. Krishna A. V., Rao. K. B. and Rajagopal A. "Effect of Different Sizes of Coarse Aggregate on the Properties of NCC and SCC", International journal of engineering science and technology, 2 (10), 5959-5965, 2010.

9. Ajamu S. O. and Ige J. A., "Effect of Coarse Aggregate Size On Compressive Strength and Flexural Strength of Concrete Beams" journal of Engineering Research and Applications, 5 (4), 67 $75,2015$.

10. Woode A. A., Amoh K. D., others,"The Effect of Maximum Coarse Aggregate Size on The Compressive Strength of Concrete Produced in Ghana" journal of Civil and Environmental Research, 7(5), 7-12, 2015.

11. Neville A. M. and Brooks j. j., Concrete Technology, Person Education, England, 2004. 
12. BS 1881-108 (1983): "Method for making test cubes from fresh concrete", British Standards Institution, London.

13. BS1881-116 (1983): "Method for determining compressive strength", British Standards Institution, London.

14. Shetty M.S., "Concrete technology theory and practice". Pub. By S. Chand and company Ltd New Delhi. 2000

15. Neville Adam. M. "Aggregate Bond and Modulus of Elasticity of Concrete ACI Materials", journal V. 94. NO. 1. January - February 1997 PP 71-74. 